\title{
Solar power generation short-term forecasting model's implementation experience
}

\author{
Elena Kochneva
}

Automated Electrical Systems Department, Ural Federal University named after the first President of Russia B.N. Yeltsin, 19, Mira St., Yekaterinburg, Russia

\begin{abstract}
Recently there is significant increase in the installed capacity of solar power plants in Russia. Thereby there are issues of solar power plants owners information support for participation in wholesale electricity market. The paper describes the experience of short term forecasting system practical implementation. The system is proposed for forecasting the solar power plant generation "a day ahead" as a part of the software for automatic meter reading systems "Energosfera". The short-term forecasting program modules structure, key parameters and characteristics used during the forecasting process description is presented.
\end{abstract}

\section{Introduction}

Energy consumption on the planet is constantly growing, and at the same time, humanity faces the task of reducing greenhouse gas emissions to prevent global climate change. Therefore, the development of renewable energy sources is becoming more and more important. Solar generation is one of the most promising and actively developing areas of renewable energy. Solar power plants are now being created in the territory of about 100 countries not by chance [1]. The pace of solar power plants development around the world in 2016 surpassed the pace of coal power station development for the first time. The International Energy Agency came to this conclusion in its report. Two-thirds of the cumulative increase in capacity of all power plants in the world fell to solar ones.

Today, in the world solar energy industry the solar energy production forecasting for short periods (day, several days, a week) does not have a tried and tested technology until the end and is often associated with large errors that may achieve $60-65 \%$. At the same time, the longer the forecast period is the more accurately one can predict the result of solar power plant output. This rule is quite correct for the area, i.e. the point forecast is always less accurate. The accuracy of the forecast increases significantly during the geographical region area increasing of for which the forecast is made.

The electricity amount forecast produced by the solar station is the prediction of the solar radiation amount that will received by solar panels. It depends on many factors, the main ones are climatic and meteorological conditions, i.e. the position of the sun in the sky, the duration of daylight, cloudiness, precipitation, wind force, etc.

Short-term solar power plants output forecasting serves to
- decrease of uncertainty in planning modes;

- creation of a tool for the participation of station owners on the day-ahead market and the balancing market; creation of a tool for the financial planning of station owners.

\section{Forecasting approaches}

There are four main approaches to forecasting the solar power plants generation [2-4]:

Physical models describe physical relationships between weather conditions, solar radiation and station power generation. The input includes a numerical weather forecast, local meteorological measurements, terrain and surface type data, as well as data on the actual the power plant output. In addition, satellite systems can be used to track the direction and speed of the clouds, which allows predicting solar radiation in real time.

Statistical models describe the relationship between the solar radiation flux density, obtained from numerical weather prediction and the generation of solar energy directly by statistical analysis of time series by retrospective data without taking into account physical processes. This method is widely used for medium and long-term solar power generation forecasting.

Adaptive and trained models use artificial intelligence systems to derive a link between the forecasted weather conditions and output power, while "learning" the model is based on the selected retrospective data. 
Initial data for calculating the solar power plant generation

\begin{tabular}{|c|}
\hline Data on the photovoltaic panels position, on the terrain \\
\hline Angle of photovoltaic panels inclination, [degree] \\
\hline Azimuth of the photovoltaic panel, [degree] \\
\hline Surface albedo, [units] \\
\hline Meteorological data \\
\hline Relative humidity, [units] \\
\hline Air temperature, [ $\left.{ }^{\circ} \mathrm{C}\right]$ \\
\hline Wind speed, [m/s] \\
\hline Solar power plant reference data \\
\hline Station wiring diagram \\
\hline Pumber of parallel panels, [pieces] \\
\hline Passport data of photovoltaic panels \\
\hline Rated power in standard conditions, [kW] \\
\hline Efficiency, [units] \\
\hline Temperature coefficient of power, [units/\%] \\
\hline Degradation of panels, [units] \\
\hline Passport data of the inverter \\
\hline Number of inverters, [units] \\
\hline of consecutively connected panels, [pieces] \\
\hline Inverter rated power at alrternative current in standard conditions, [kW] \\
\hline Inverter rated power at constant current in standard conditions, [kW] \\
\hline Temperature coefficient of power, [units/\%] \\
\hline Maximum inverter efficiency, [\%] \\
\hline
\end{tabular}

Initial data for calculating the power of a solar power plant

\begin{tabular}{|c|}
\hline Calculation of the solar radiation flux density on an inclined plane \\
\hline Scattered radiation, $\left[\mathrm{W} / \mathrm{m}^{2}\right]$ \\
\hline Direct radiation, $\left[\mathrm{W} / \mathrm{m}^{2}\right]$ \\
\hline Anisotropy coefficient, $[\mathrm{units}]$ \\
\hline The solar radiation flux density on the inclined panel, $[\mathrm{W} / \mathrm{m} 2]$ \\
\hline Calculation of panel operation mode \\
\hline calculation of the photocells temperature, $\left[{ }^{\circ} \mathrm{C}\right]$ \\
\hline Average panel power for 1 hour, $[\mathrm{kW}]$ \\
\hline Calculation of inverters operating mode \\
\hline Power consumption of inverters, $[\mathrm{kW}]$ \\
\hline Output power of inverters, $[\mathrm{kW}]$ \\
\hline \\
Solar power plant output, $[\mathrm{kW}]$ \\
\hline
\end{tabular}

Fig 1. Solar power plant output forecast block diagram.

Unlike the statistical approach, the learning approach uses algorithms that can implicitly describe complex nonlinear relationships between weather conditions and the power generated by the power plant, which can not always be taken into account in statistical analysis. For both statistical and learning models, the determining value for the accuracy of the forecast renders a sample of the input data used in constructing the model.

Combined forecasting models are often a combination of physical and statistical models. The physical approach is not always justified because of the complexity or impossibility of taking into account certain factors, which requires the introduction of a statistical approach for their determination.

The statistical approach can have considerable accuracy in calculating the averaged values of solar radiation power over a long period of time (day, month, year), but it has much less accuracy in a shorter time interval (minutes, hours) when physical processes, for example, cloudiness, can not be averaged over a given interval. Optimum accuracy of combined models is achieved by adjusting statistical models to constantly changing conditions described by physical models.

Taking into account the specifics of the task to be solved such as the creation of a solar power plant operational and short-term forecasting system, as well as the initial information limited and uncertainty in the absence of retrospective data, it is most appropriate to use physical models that make possible to obtain a forecast for the station based on the minimum composition of the forecast meteorological information. In order to refine the estimates obtained, statistical models are additionally implemented. The solar power plant generation forecast is based on the calculation model of solar radiation intensity at the power plant territory. 


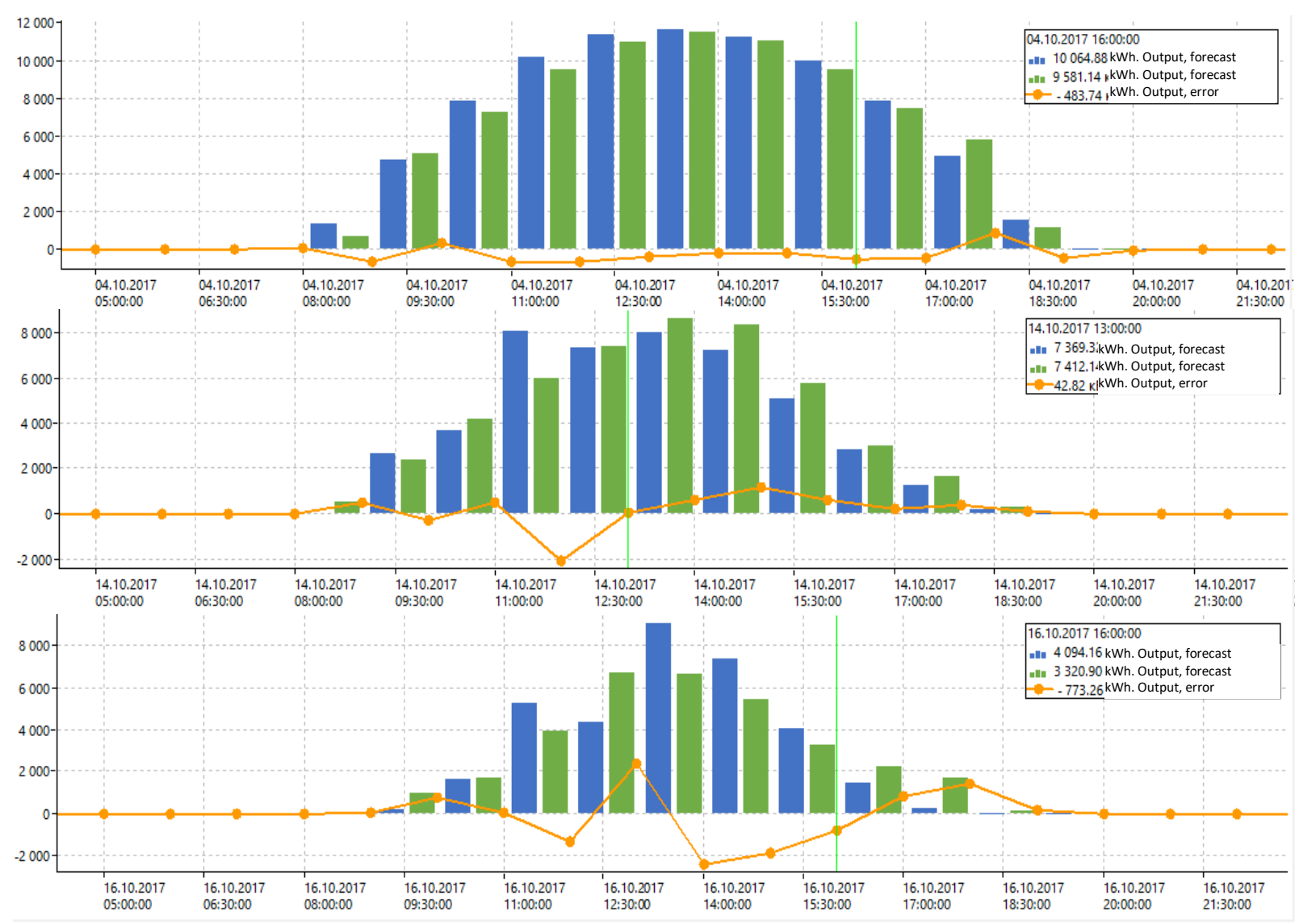

Fig 2. Power plant generation short-term forecast examples

Table 1. Short-term forecast error parameters

\begin{tabular}{|c|r|r|r|}
\hline Date & Average cloudiness, p.u. & $\begin{array}{c}\text { Average error for the period, } \\
\text { MAPE, \% }\end{array}$ & Standard deviation, $\%$ \\
\hline 04.10 .2017 & 0,00 & 1,426 & 2,818 \\
\hline 14.10 .2017 & 0,76 & 1,088 & 5,294 \\
\hline 16.10 .2017 & 0,90 & 0,491 & 9,126 \\
\hline $01.10 .2017-31.10 .2017$ & 0,55 & $-2,740$ & 20,731 \\
\hline $01.11 .2017-30.11 .2017$ & 0,62 & $-4,753$ & 17,253 \\
\hline $01.12 .2017-31.12 .2017$ & 0,63 & $-6,318$ & 19,058 \\
\hline
\end{tabular}

\section{Solar power plant output forecast}

The solar power plant generation forecast is based on the calculation model of solar radiation intensity at the power plant territory [5]. Calculation of the solar radiation incident on the photovoltaic panel surface includes the determination of three values, which are solar radiation on the boundary of the earth's atmosphere, solar radiation on the horizontal surface of the earth and solar radiation on the inclined surface [6-7].

The value of solar radiation on the boundary of the earth's atmosphere is calculated from the geometric model of the Sun's motion. The value of the solar constant which is $1367 \mathrm{~W} / \mathrm{m} 2$, the angle of solar declination for a given day in a year, as well as the dependence of the solar radiation on the geographical position (longitude and latitude) of the calculated point are taken into account.
To estimate the change in the solar radiation during its passing through the Earth's atmosphere, the transparency coefficient is used. The coefficient of transparency takes into account the absorption and reflection of solar radiation into outer space by different layers of atmosphere. The calculation of this coefficient is performed on the basis of the regression model, including the actual and forecast cloud data, as well as the mean values of the angular height of the sun within the specified time step [8].

The cumulative energy flux density (intensity) of solar radiation at the earth's surface incident on the inclined surface is the sum of direct radiation and scattered radiation. Direct radiation is determined from the calculation of solar radiation on the boundary of the earth's atmosphere, transparency coefficient, the angle of inclination of the panels, and the scattered radiation depends on the reflectivity (albedo) of the earth's surface and the humidity of the air.

After receiving the values of the solar radiation falling on the photovoltaic panels, a forecast is made for 
the generation of electricity from the solar power plant. The nominal power of the photoconductor, the reduction in the overall efficiency of the panel, the calculated value of intensity) of solar radiation at the earth's surface incident on the inclined surface, the panel efficiency, the panel's temperature coefficient, ambient temperature and wind speed are taken into account when calculating the generation power of a photoconductor.

To calculate the solar plant total power, the total number of photovoltaic panels participating in the generation of electricity for a given time interval is used. In addition, losses in $\mathrm{AC}$ and $\mathrm{DC}$ installations, i.e. inverters, transformers and conductors of the power station electrical network are taken into account [9-10]. Determination of solar power plant electricity generation hourly values is carried out in accordance with the block diagram shown in figure 1.

\section{Forecast error evaluation}

The average absolute error in percent of MAPE is used to analyze transparency coefficient short-term forecasting models. During the foreign experience analysis the impossibility of MAPE error evaluation criteria in a traditional form using for the statistical evaluation of the significance and comparative analysis of the solar energy forecasting model efficiency was established. The solar power plant installed power is assumed as a value, in relation to which the generation forecast MAPE error is calculated [7].

$$
M A P E=\frac{1}{N} \sum_{i=1}^{N}\left|\frac{\bar{P}_{i}^{\text {fact }}-\bar{P}_{i}^{\text {forecast }}}{P_{P V}}\right| \cdot 100 \%
$$

where MAPE is the average absolute error in percent, [\%]; $N$ is the quantity of observations; $i$ is the number of the observation; $\bar{P}_{i}^{\text {fact }}$ is the solar power plant active power generation actual value for i-th observation, $[\mathrm{kW}]$; $\bar{P}_{i}^{\text {forecast }}$ is predicted value of solar power station active power generation for i-th observation, $[\mathrm{kW}] ; P_{P V}$ is the installed capacity of solar power station, $[\mathrm{kW}]$.

\section{Model practical realization}

At the moment the short-term forecasting system is introduced into trial operation as part of the software package "Energosfera 8.0" at Zavodskaya solar power plant.

As part of the solar power plant main equipment, there are solar panels with a nominal power of 270 watts (the total number is 56,600 units). The total number of installed inverters is 16 .

The solar panels have a south orientation and an inclination angle of 30 degrees, there is no solar tracker.

Meteorological information comes with a discreteness of 1 hour from an external weather provider and includes: forecast cloudiness, air temperature, humidity, wind direction and speed.

Examples of calculating the solar power plant generation forecast "a the day ahead" are presented in figure 2 for the following types of weather conditions: clear, cloudy with clearings, overcast respectively. The forecasting error summary parameters in percent relative to the installed capacity of the power plant for OctoberDecember 2017 are presented in Table 1.

\section{Conclusion}

As a result of the system pilot integration, the necessary statistical data was collected at the operating solar power plant. These data are necessary for modernization and improvement of the forecasting system. The forecast error established to the solar power plant for the period from October 1, 2017 to December 31, 2017 was 4.6\% which is comparable to the accuracy of global practice forecasts. The error standard deviation for the period under consideration is estimated at $19 \%$. Deviation occurs due to the random nature of weather conditions, as well as the provider weather forecast error.

The presented system of solar power plant generation short-term forecasting "a day ahead" is universal and can be used at any operating solar power plant facility as part of the software package "Energosfera 8.0" produced by ProSoft Systems Ltd.

To date, ProSoft Systems Ltd together with with Ural Federal University is developing a short-term forecast prompt correction system based on solar radiation energy flux density current measurements. This correction will ensure the possibility of solar power plant owners participation in wholesale market intradaily trading procedures.

\section{References}

1. List of renewable energy projects selected according to the results of competitive selection in accordance with the Registry of selection of investment projects for construction of generating facilities operating on the basis of renewable energy sources/ Association of noncommercial partnership "Market Council". URL: https://www.atsenergo.ru/vie/proresults

2. Heinemann, D., Lorenz E., Girodo M. Forecasting of solar radiation. Oldenburg University, Institute of Physics, Energy Meteorology Group.

3. Bacher, P., Madsen, H., HA Nielsen Online shortterm solar power forecasting. Solar Energy. Vol 83, Issue 10, October 2009: 1772-1783. (2009)

4. C. Chen, S. Duan, T. Cai, and B. Liu, "Online 24-h solar power forecasting based on weather type classification using artificial neural network," Solar Energy, vol. 85, no. 11, pp. 2856-2870. (2011)

5. Software package Energosfera / ProSoft Systems Ltd. URL: http://www.prosoftsystems.ru/ catalog/show/programmnyj-kompleks-jenergosfera1

6. D.A. Snegirev, R.T. Valiev, S.A. Eroshenko, A.I. Khalyasmaa. Functional assessment system of solar power plant energy production. Proceedings of the $8^{\text {th }}$ International Conference on Energy and Environment (CEIM). Pp 397-353. (2017). 
7. D.A. Snegirev, R.T. Valiev, S.A. Eroshenko, A.I. Khalyasmaa. Algorithmic realization of short-term solar power plant output forecasting. Proceedings of the II International Conference on Control in tecgnical systems (CTS'2017). Pp 228-231. (2017).

8. Guidance Document 52.27.724-2009 «Manual on Short-Term Weather Forecasts of General Purpose» / URL: http://docs.cntd.ru/document/437152648

9. Chiou-Jye Huang, Mao-Ting Huang, and ChungCheng Chen. A Novel Power Output Model for Photovoltaic Systems. International Journal of
Smart Grid and Clean Energy. № 2. - Pp 139-147. (2013)

10. D.L. King, S. Gonzalez, G. M. Galbraith and W. E. Boyson. Performance Model for Grid-Connected Photovoltaic Inverters. Albuquerque, NM, Sandia National Laboratories. 47 p. (2007)

\section{Acknowledgements}

The work was supported by Act 211 Government of the Russian Federation, contract № 02.A03.21.0006. 